\title{
Study on Innovation of Government Management Mode
}

\author{
Ying SUN
}

Liao Ning Academy of Governance, Shenyang, P.R. China, 110161

Keywords: Innovation, Government management, Mode, Function.

\begin{abstract}
The innovation of government management refers to the government organizations constantly adapt to changes and volatile external environment, through the formation of structure, process, mechanism and new behaviors, explore and establish reasonable system of government operation mode, so as to ensure the optimal allocation of social resources to ensure the realization of public interest to the greatest extent. Mainly includes the concept of government management innovation, system innovation, management innovation, method and mechanism innovation. The concept of government management innovation is further deepen the level of thinking and understanding, the change of thinking habits and the creation of the theory of government; Institutional innovation is to change a kind of system arrangement, the realization process of the value; The government management innovation is the government process reengineering, improve the service mechanism, reform supporting mechanism of government management; The method innovation of government management is the government operation mode and process.
\end{abstract}

\section{Introduction}

What government functions should be solved is what the government should do, and what the administrative management mode should be solved is how the government should perform its functions. All along, the transformation of government functions has been the focus of government work. Administrative management mode is always around the function of the government. Today we see the government has some unsatisfactory place, and the reason is not the purpose but administrative management mode.

\section{Development Process of Government Management Mode}

Now the Chinese government management mode is gradually changing from traditional to modern process. Since 1949, the development of our government management mode can be divided into three stages.

\section{Political Oriented Government Management Stage (1949 1978)}

Its main features are: with mandatory regulation as the main management mode, take the political position, political consciousness, political performance as the main criteria for the appointment and evaluation of officials. The government management mode while promoting China's economic and social development in a certain period 
of time. But from a long-term and macro perspective, this kind of government management mode is the source of the economic and social trend of decline. Because the planned economic system is suitable for the accumulation not suitable for business, and finally to the market economy is the inevitable history.

\section{Economic Oriented Government Management Stage (1978 2003)}

During this period, the ruling party and the government completely negate the class struggle as the outline of the political objectives and government functions, and gradually formed the basic line of the primary stage of socialism. At this time, the whole modernization of Chinese society has been greatly pushed forward. The ruling party and the government began to develop the economy, mobilize the enthusiasm of all the people as the basic goal of government management, the mode of government management is beginning to change from mandatory, single, direct to diversification and science.

\section{Service Oriented Government Management (since 2003)}

During this period, the ruling party and the government summed up the experience and lessons of the previous stage of development. Clearly put forward the strategic goal of building a service-oriented government, a clear positioning of the government transformation. At the same time, put forward specific requirements for the transformation of government management mode.

\section{Government Management Mode Innovation Regulation}

First, to improve the ruling ability is its core objective. In a way, this is the most characteristic of Chinese local government innovation. Second, public service innovation has become the focus of local government innovation, And in the future development, the proportion will expand. Including health, pension, culture, education, etc..

\section{Innovation Approach -- Institutional Innovation}

\section{Innovation of Social Management System}

We must focus on maintaining the fundamental interests of the overwhelming majority of the people, and the maximum increase in the harmonious factor. Social contradictions have reached the joint point, social management must follow up. If social contradictions and social demands of the masses cannot be effectively resolved, the society will have a problem. The government uses one way management to control the trend of multi society, it is easy to set all kinds of contradictions in a body, but the social organization can be used to do the firewall and the isolation.

\section{Innovation of Basic Management System}

With the acceleration of the urbanization process and the improvement of the awareness of the residents' autonomy, a large number of social and public affairs gradually return to the local government, and the grass-roots organizations begin to take more management functions. Basic level government is the most direct 
perception and response of social problems. The quality of the work of the grass-roots cadres, directly related to the masses of the party and the government's views.

In Chinese history, the tradition of local autonomy has long maintained. To recognize the power of society, to make some of the functions back to the society, this is also the wisdom drawn from the traditional culture. The government promote the social diversity of governance is the guarantee of China's long-term stability.

\section{Industry Management System Innovation}

Government industry management tools are also more emphasis on the development of industry policy, industry planning, coordination services, business activities carried out on a regular or irregular inspection and supervision and inspection, etc.. The government tries to make the industry management as a continuation of the function of government macro regulation, which is lack of scientific basis, it is difficult to achieve. Industry management as the function of the government is not conducive to the development of the industry enterprise, also does not conform to the public interest. The departments in charge of industry despite get out from the planned economy mode of enterprise micro intervention, but still be used to stand in the perspective of business executives, ignoring the role of representative of the public interest. We need to change this phenomenon.

\section{Innovative Approach - the Innovative of Management Mechanism}

\section{Government Process Reengineering}

The government is cautious, the market is dynamic; the government has the responsibility to play, the market is confident. Let the government to keep up with the rhythm of the market, make full use of the visible hand. Cancellation and decentralization of administrative examination and approval matters is a major reform of the current government to vigorously promote, is the government's self revolution.

Let "decentralization" implement, to realize the transformation from decentralization to substantive rights form. This is the key to the release of reform dividends and bonus system. It is also the main drive to improve economic developments.

\section{Service Mechanism Innovation}

More than a hundred years ago, French political scientist Tocqueville pointed out that social unrest is often not in the place of economic stagnation, but may occur in the place of economic growth. This is the challenge that China is facing now. From 1978 to today, China has achieved a thousand years of economic growth in the history. Through thirty years of reform and opening up and modernization into the second half, China has entered the critical years of the government transformation and the mode of economic development. Many risks of social transformation are testing the wisdom of the Chinese leadership. In addition to China, all the countries with land area of more than 3000000 square kilometers are the implementation of federal system, as Russia, Canada, the United States, Brazil, Australia and India. For the vast land area, the economic, social and cultural differences between the various regions of the country, 
It is very difficult to provide quality and efficient public service to the whole society by the central government. In the current financial, material, capacity, how can the government provide quality public services to meet the needs of the public? The important ways including government purchase services, PPP mode, public service standards, etc.

\section{Support Mechanism Innovation}

The innovation of government management mode is definitely worth encouraging, but cannot be wishful thinking. The government's most need support, including legal support, leadership support, team support, public opinion, public opinion support, etc.. Leadership's support is very important, because $58 \%$ of the innovation idea is first proposed by a knowledgeable leader. And leadership support or superior departments recognized as the most innovative process of external support.

In addition, but also pay attention to the support of public opinion. In order to get the support of public opinion, the key is empathy, compassion. So we want to use the right, serious attitude towards the people. We do not have tradition to questions about the government. People tend to have a higher trust in the government as a whole. To get support from the public, we must treat "social phobia" firstly. The fundamental characteristics of public political are reasoning and calm, and the fundamental characteristics of violence are silent and fanaticism. Normal expression of society is not terrible, what we should do is to regulate the expression of public opinion, pass a positive energy. This process will also make the government management a huge leap.

\section{Innovative Ways -- the Innovation of Formal Methods}

\section{Government Means Innovation}

In recent years, with the development of network technology, the level of e-government construction has been greatly enhanced, greatly enhancing the service oriented government's ability to govern. At the same time, ultra high-speed broadband network, a new generation of mobile communication technology, cloud computing, networking and other new technologies are emerging, Promote the use of online office, information resources sharing, building a multi-level electronic monitoring system and other means. So we have a lot of room for improvement.

\section{Evaluation Method Innovation}

Performance evaluation, particularly in the evaluation results linked to the corresponding incentive and accountability mechanisms, can effectively stop the loss of government behavior and the phenomenon of waste, promote the government in the administrative management of a prudent choice and measure, rational allocation and use of administrative resources, So as to reduce the administrative costs, improve the administrative efficiency. Performance evaluation cannot focus on the sensational effect, but cannot become another form of image engineering. 2014, the State Council launched a comprehensive inspection. And on the basis of self inspection and field supervision, the third party assessment become the biggest innovation and highlights of the inspection. 


\section{Innovative Ways -- Value Idea Innovation \\ Efficient ---High Efficiency with Legitimacy}

The administrative efficiency is the important standard to measure whether the administrative management activity is scientific or not, and it is the basic goal of the administrative management.

As a backward country, sometimes we have established a "catch-up" system. Over the past sixty years, all levels of government officials are pursuit of high efficiency and high speed with regardless of what things do. In China's political vocabulary, it is full of words that describe high speed. These frequent key words, all convey a sense of speed supreme.

The government should control their own injustice, the efficiency of the individual officials also to overcome the low efficiency of their lazy governance. Diligent should become a habit.

\section{Democracy -- a Modern Life}

Democracy is negotiated management. As Hayek said: the compulsion is a kind of evil. Modern countries should make the daily life of democracy and promote democracy in daily life. So we want to promote the people through a variety of opportunities to participate, to express their will, to protect their own interests.

\section{Fair - the Fair process that can be seen}

Promote social equity is the idea that the government of the past 10 years. Social justice is a more and more important position in the guiding principle of government policy. To promote social justice is the conscience of the government. In the field of social fairness and justice, an important aspect is satisfied the basic needs of all members of society includes the sick and elderly, other vulnerable groups. So our management must be fair and equitable.

\section{Transparent - zero Distance and "glass cylinder government"}

Promote the operation of the power of public, standardized, the people's supervision, so that allow power to operate under full supervision and control. In fact, we hope that the government's transparent management, the purpose is to give the public a basic sense of security. This security is one of the most important values of our government, Let people know that our government is worthy of trust. Otherwise, people's sense of security will be nowhere to put.

\section{People Oriented -- public Life with Dignity}

Our society is a person's society, a society develops more quickly, more should respect people's basic right. Deng Xiaoping once said: "for China, the most important human right is the right to exist, the lowest right to exist is to maintain the right of life. The right to exist is a continuous development, and now the right to life also refers to the right to maintain the quality of life. Because the system itself is a commitment to moral responsibility. What we need now is precisely the right to respect and reverence for life, and reflect on the general rules. 


\section{Conclusion}

In this process, we should avoid the three problems: First, don't make innovation a slogan.

To get down to do it, but also normalize the innovation. Now, about $1 / 3$ China Award for innovative projects have cease to exist except in name. Reform and innovation in the direction of social progress, even stop in this place, in other places it will be picked up by other people to do. Valuable things, but also must be a thing of life. Not because of the reformers left, or suffered a temporary setback, the results of the reform will be buried. As long as there is a suitable soil, it will be born again. Second, don't put “innovation ideology. Think that all new, never seen, foreign thing is good, it is not objective. Third, don't turn innovation into a bonsai.

The rapid transition period is the trouble period of national and individual growth. From the related social issues emerge until the time of the relevant system reform to calculate, China modernization pace is roughly ten times faster than the average level of the western countries. Ten years of new China, roughly equivalent to one hundred years in the west, this speed will significantly enlarge the country and the individual growth of trouble. For us, to do scientific and effective governance, with the power of the government. This is the standard and the ultimate goal of the innovation of our administrative management.

\section{References}

[1] Deng Mingfen. Research on social organization and government construction [J]. Social organizations in Shanghai. 2009.3.19(in Chinese) (in Chinese)

[2] Civil Service Integrity Value and Construction [Z]. Baidu Library. 2011.3.12 (in Chinese).

[3] Ma Xian-quan. Leading Cadres Should Enhance Service Consciousness And Ability [N]. The River Network. 2008.11.4 (in Chinese).

[4] Peters cover. The public policy of the United States -- commitment and implementation. Shanghai: Fudan University press, 2008:62. 